\title{
Technetium Tc-99m Hydroxydiphosphonate
}

National Cancer Institute

\section{Source}

National Cancer Institute. Technetium Tc-99m Hydroxydiphosphonate. NCI Thesaurus. Code C94222.

A radioconjug ate containing hydroxydiphosphonate (HDP) labeled with the metastable radioisotope technetium Tc $(99 \mathrm{mT})$, with radioimag ing activity. Upon intravenous administration, skeletal uptake of technetium T c-99m HDP occurs as a function of skeletal blood flow and osteogenic activity. HDP has a specific affinity for hydroxyapatite crystals in bone where abnormal accumulation of increased osteoid mineralization has occurred. Labeling of HDP with 99mT c allows gamma scintig raphic imaging of areas of abnormal osteogenesis associated with malignant bone lesions. 